\title{
The Study of the Optimizing Strategy of Chinese Teaching of Literature for Children in Primary School
}

\author{
Mingxiu Ding \\ Jilin Engineering Normal University, 130052
}

574255187@qq.com

Keywords: Chinese Teaching of Primary School; Literature for Children; Optimization of Teaching

\begin{abstract}
Children's literature plays an important role in literature treasure and has the enlightening significance for children. The teaching for children's literature is the guiding education for the development of pupils' mentality, emphasizing the deep interpretation of literariness, storytelling and philosophy. Teaching strategy for children's literature needs to be optimized continuously so that it can conform to students' individualities. In addition to the situational teaching, teachers need to combine the inquiry-based teaching and collaborative teaching and with the help of the multidimensional interaction guide students to transform their own learning from passive one to active enquiry-based one, thus realizing internalization and explicitness, and achieving the optimization of teaching strategy.
\end{abstract}

\section{Introduction}

Chinese teaching of primary school is a significant subject in the basic education. Under the background of implementing quality education to a great degree in China, both teaching content and teaching manner contain the important ways of education[1], thus playing an important role in the growth of children's mentality. Literature for children, as the teaching model which takes a lot of space in Chinese textbook of the primary school, combine the storytelling, and literariness with interestingness, which is more suitable for children's learning interest and reading habit. Teaching content containing some life philosophies and conforming to children's understanding level usually explains the profound things in simple words.[2] Therefore, grasping the characteristics of literature for children and optimizing the teaching strategy in a profound way can improve teaching efficiency greatly.

\section{The Importance of Literature for Children for Children's Growth}

Literature for children refers to those literary works intended for children. Its words are very simple, its contents are very rich and it has vivid plots, which all conforms to the learning characteristics of children[3]. So, what are the leaning characteristics of children? Learning characteristics of children is determined by their cognitive development stage. Piaget, the famous educator, has divided children's cognitive competence in this stage into the preoperational stage and the concrete operational stage. Students in preoperational stage are still in sensorimotor stage in which their thoughts are not logical but unitary, irreversible and static. While students in concrete operational stage are equipped with basic logical thinking and their thoughts are multi-dimensional, reversible and dynamic[4]. All these characteristics will exert a great influence on the students' reading interests and learning habits directly and the teaching method and teaching efficiency indirectly. Literature for children is aimed at learning characteristics of children, thus being in accordance with their point of view from the perspective of content, plot and language.

We can say literature for children plays a very important role in the children's growth and development and is also the indispensable role in Chinese teaching of the primary school. First, it covers a great scope, including fairy tales, fables, idiom stories and folktales, children's poems, children's jokes, even historical stories on the whole Chinese[5]. Owing to its abundant and extensive contents and vivid and tortuous plots, literature for children is profoundly loved by children. What's more, literature for children is created on the basis of the psychological pursuit of 
pursuing happiness and eliminating bitterness. For the purpose of intriguing children's reading interests, author usually creates short stories, work out straightforwardly the climax attracting children and avoiding using long description which can demotivate children's reading interest. Meanwhile, the main plot of story is highlighted, and the images of characters are very bright in order to intrigue students' curiosity. What is the more important thing is that literature for children has the instructive meaning, which makes students gain some thoughts and obtain some mental acquisitions except reading itself.

\section{Optimization Strategy for the Teaching concerning Literature for Children}

Literature for children has the significant status in their reading for their growth and development. It has five great characteristics including storytelling, enlightening, interesting, figurative and intellectual characteristics, which is the fundamental reason for its popularity among teachers and students[6]. Therefore, in ordinary teaching, in order to grasp the advantages of literature for children, teachers need to combine children's reading habits and learning characteristics and continuously optimize teaching strategy thus enhancing teaching quality.

Situational Teaching Strategy. In the Chinese textbook of primary school, literature for children is presented by the form of various stories such as, fairy tales, idioms and folktales so on. The characteristics of these stories are that the author creates the story situation and use words which arouse readers' emotional resonance and make readers produce heart collision with the author and realize the emotional and cognitive interaction thus achieving the deep comprehension of thoughts. Therefore, situational teaching is produced, which refers that teachers, in the teaching process, create the corresponding story background with a view to leading students to enter the story situation even become the characteristics in the story thus arousing students' firsthand experience[7]. This teaching method is usually used to trigger students' emotional resonance.

In the literature for children Chinese teaching classroom teaching activities of primary school, situational teaching strategy is a teaching method extensively used in teaching activities and achieving great teaching efficiency. In this teaching method, teachers work as the leading role and employ multimedia teaching equipment to establish the teaching situation corresponding with teaching content. For instance, when teachers teach idioms such as better late than never and one's action was opposite effect to one's intention, they can use multimedia to play the corresponding the animation clips. Vivid background is able to easily attract students' attention and intrigue their curiosities and make them immerse in the story plot. When teach fairy tales such as The Little Match Girl, teachers can play the excerpt from a cartoon of the same name and then explain the text as the students watch the screen, taking the expounding of the story in cartoon as the theme and inserting teaching content and arouse students' learning interests through setting up the special situation. Meanwhile, in the teaching process, teachers can use questioning strategy to lead the students to research the story plot and characters' mental activities so that they can form the tridimensional and multi-dimensional interpretation for the works.

Exploring the Teaching Strategy. Interest is the motivation for learning. One of the teaching objectives of Chinese teaching of primary school is to develop students' automatic reading interest with a view to fostering reading habit. Teachers' guidance is indispensable in this teaching process, but what is more important is the students' engagement. The more students engage into the classroom activities, the more they bury themselves in the atmosphere. Otherwise, they will have little interest in the classroom teaching activities. So, how to improve their engagement into the classroom activities? The most common way is to use enquiring teaching strategy. Inquiring teaching strategy refers that teachers, in the teaching process, through the questioning and guiding way, guide the students to accomplish the learning tasks such as the automatic learning, inquiring the questions and also the collaboration and communication and so on, thus making them transform from passive learning to active learning. (7) This teaching strategy excavates the students' thought potency furthest and takes intriguing the students' interest as the starting point, and through continuously set the questions and explore the answers and then satisfy the interactional request of 
classroom teaching.

In terms of the storytelling and thought-provoking characteristics in literature for children the work itself, it is very hard to achieve the teaching efficiency through the teaching method of imparting knowledge. And also in this way, it is difficult for the students to enter the story plot thus hardly communicating with the author through heart. Inquiring teaching method solves the profound problem that students cannot understand the textbook very well. First, teachers, through setting the teaching situation, artificially restore the story background leaving the students immersing in this background. Second, teachers lead the students to finish one reading link after another. For instance, the question like why did the little girl go to sell the match can achieve the reading purpose of intriguing the students' reading interests. Third, teachers can use this question to lead the students to explore the overall meaning of the text in a profound way thereby making students comprehend the connotation of the text and achieve deep interpretation the author' thoughts of composing this story. Fourth, teachers can set up the collaborating and communicating link providing e the space for the interactive inquiry, in which students can communicate the inquiring and thinking consequence of and learn from each other and then internalize the knowledge.

Group Cooperation Teaching Strategy. In the inquiring teaching strategy, we can easily find that with the reading teaching's penetrating, the interactive communication among the students gradually increases. Thus, students will discuss the questions raised by the teachers more freely, which is called group cooperation teaching strategy. This teaching strategy mainly highlights the dominant position of the students. Made up by two or more students, the learning group takes the common learning task as the objective of cooperative learning and in this learning process, teachers work as the guider or instructor to help students finish the learning tasks and evaluate the whole group grade, aimed at emphasizing the group and collaborative spirit and weakening the students' thought of self-centeredness[9].

The biggest characteristic of collaborative learning is to develop the students' self-control competence and the ability of automatic thinking. Especially, the automatic thinking ability is exactly the ability required to interpret literary works for children. Many works have profound meanings and contain abundant life philosophies. What's more, students have different family background, living environment and thinking ability, which makes them have different opinions about the literary works. The most conspicuous characteristics of collaborative learning is to provide the space for the students to express their own thoughts and also for them to grow properly, facilitating the understanding among the students and among teacher and students, and enhancing their enthusiasm about Chinese and literature for children. Meanwhile, teachers take over the leading role of the classroom to the students and themselves works as assistants. All these make the students breakthrough themselves continuously and build up their confidence and transform from the passive role to positive role.

Multi-dimensional Interactive Teaching Strategy. The organization and implementation of teaching activities for literature for children need both teachers and students' common endeavor. Teachers as the designer, organizer and executor of teaching activities play the role of commanding the progress of teaching activities. While, owing that the students work as the participator and evaluator in the teaching-learning activities, their experience feeling and degree of participation directly influence the quality of the teaching activities. Therefore, the teaching activities for literature for children cannot be separated from the interactive teaching. Interactive teaching is a kind of teaching strategy which is based on the interaction among the students and also among the teachers and students, and can through the interactive influence among the students enhance their mutual understanding, produce teaching resonance and improve teaching activities and optimizing teaching structure[10].

Owing to its abundant content, literature for children needs to be interpreted from many perspectives. What's more, the individual differences of the students also cause their distinguished feeling for the same article. Therefore, teachers need to add interactive elements in the teaching activities and get the students to find suitable interactive model in the teaching-learning activities. 
The interactive model among teacher and students is the most common one in which through questioning, guiding answering and explaining, teacher and his students establish the friendship-like communicative relationship. This makes the introvert students feel more relaxed thus being willing to express their thought. The interactive model among the students is more suitable for extrovert students. Through the classroom interactive activities such as role play, students can play some characters in literary works thereby integrating the students themselves into the literary works and making them realize more deep interpretation and equipping them with different comprehension and therefore enhancing the teaching quality.

Literature for children is the important reading material accompanying children's growth and also the model for enlightening education. Literature for children is written for children's growth but through the children's point of view, readers can observe the world and understand the life. It puts the interestingness and thought in the first place and integrates literariness with instructive feature and use simple words to express profound life philosophy exerting great influence on the children's growth. In the teaching process, aimed at the features of literature for children extensively, teachers use the teaching strategy in their teaching such as situational teaching, inquiring teaching, collaborative teaching and multi-dimensional teaching strategy in order to satisfy the distinguished demands for different students thus making Chinese of primary school more amusing and vivid and also leaving the students learn and grow in happiness.

\section{References}

[1] Yi Chen: Education in Chinese Language Teaching in Primary Schools[J], Teacher, 2016(10): 18 .

[2] Miao Pan: Reading Teaching should Pay Attention to the Characteristics of Children's Literary Works[J], Guangxi Education, 2016(45): 94.

[3] Xiaomei Tang: Reflections on Teaching Children's Literature in Primary School Chinese Textbooks[J], Primary School Teaching Research, 2017(8):85-86.

[4] Liansheng Pi: Educational Psychology (Fourth Edition)[M], Shanghai: Shanghai Education Press, 2006, (10): 252-253.

[5] Yujuan Liu and Xiuqiao Liang: The Teaching Strategy of the General Story Text[J], Beijing Education (General Edition), 2013(9):71-72.

[6] Haiping Liu: The Status and Role of Children's Literature in Primary School Chinese Education[J], Exam Weekly, 2015(7):42-42.

[7] Jing Cui: Application of Situational Teaching Method in Primary School Chinese Teaching[J],Reading Digest, 2017(13):210-211.

[8] Junhua Li: Analysis of Autonomous, Cooperative and Exploratory Teaching Mode in Primary School Chinese Teaching[J], University Entrance Examination, 2015(6):54.

[9] Jiu Gao: On Group Cooperative Learning[J], Modern Education Science(Primary School Headmaster), 2012(7):146-147.

[10] Duohong Wang: A Probe into the Interactive Teaching Mode between Teachers and Students[J], Education Science: Citation Edition, 2016(8):164. 